\title{
CRISES E PRECIFICAÇÃO DE ATIVOS NO MERCADO DE CAPITAIS BRASILEIRO: OS CINCO FATORES DE FAMA \& FRENCH
}

\author{
CRISIS AND ASSET PRICING IN BRAZILIAN STOCK MARKETS: \\ THE FAMA-FRENCH FIVE FACTORS
}

\section{KLEVERSON DÁLITON SILVA MOREIRA}

Universidade Federal de Uberlândia (UFU)

Mestre em Administração - PPGA / Universidade Federal de Uberlândia (UFU)

Orcid: http://orcid.org/0000-0002-4393-284X / E-mail: kleversondaliton@hotmail.com Av. João Naves de Ávila, 2121, Bloco 1F - B. Santa Mônica, Uberlândia-MG, CEP: 38.400-902

\section{ANTONIO SERGIO TORRES PENEDO}

Docente do PPG em Administração - Universidade Federal de Uberlândia (UFU) Doutor em Engenharia de Produção pela Universidade Federal de São Carlos (UFSCAR)

Orcid: http://orcid.org/0000-0001-7763-8457 / E-mail: drpenedo@gmail.com

\section{VINICIUS SILVA PEREIRA}

Docente do PPG em Administração - Universidade Federal de Uberlândia (UFU) Doutor em Administração pela Fundação Getúlio Vargas (FGV)

Orcid: http://orcid.org/0000-0002-4521-9343 / E-mail: viniciuss56@gmail.com

\section{MARCELO AUGUSTO AMBROZINI}

Faculdade de Economia, Administração e Contabilidade de Ribeirão Preto (FEA-RP/USP)

Professor do PPG em Controladoria e Contabilidade - FEA-RP/USP

Doutor em Administração de Organizações - FEA-RP/USP

Orcid: http://orcid.org/0000-0003-0933-6064 / E-mail: marceloambrozini@yahoo.com.br

Submissão: 09/05/2019. Revisão: 13/10/2020. Aceite: 01/02/2021. Publicação: 01/03/2021.

DOI: http://dx.doi.org/10.22277/rgo.v14i2.4893

\section{RESUMO}

O mercado de capitais é importante para o desenvolvimento do país, remunerando aplicadores e possibilitando aplicação dos valores em atividades produtivas. Contudo, quebras estruturais, sejam estas locais em âmbito internacional, levam à alteração das relações dos fatores de risco relacionados ao retorno das ações ao longo do tempo, inviabilizando a utilização de técnicas de precificação de ativos. Desta maneira, este estudo tem o objetivo de identificar como instabilidades econômicas influenciam no comportamento dos Cinco Fatores de Fama \& French em relação ao retorno das ações negociadas no mercado de capitais brasileiro, aplicando regressões com dados em painel utilizando os Cinco Fatores de Fama \& French, considerando diferentes períodos macroeconômicos. Os resultados demonstram que os fatores são aplicáveis ao mercado brasileiro, sendo que todos apresentaram relações estatisticamente significantes. Além disto, foi possível observar que períodos de crise, afetam as relações verificadas, indicando maior sensibilidade ao risco por parte dos investidores, principalmente ao analisar as variáveis tamanho e nível de investimento.

Palavras-chave: Mercado de Capitais. Precificação de Ativos. Cinco Fatores de Fama \& French. Crises. Períodos Macroeconômicos. 
Kleverson Dáliton Silva Moreira, Antonio Sergio Torres Penedo, Vinicius Silva Pereira

e Marcelo Augusto Ambrozini

\begin{abstract}
The capital market is important for the development of the country, remunerating applicators and making possible the application of values in productive activities. However, structural breaks, whether these sites are international, lead to a change in the relationship of risk factors related to the return of shares over time, making it impossible to use asset pricing techniques. In this way, this study aims to identify how economic instability influences the behavior of the Five Fame \& French Factors in relation to the return of the shares traded in the Brazilian capital market, applying regressions with panel data using the Five Factors of Fame \& French, considering different macroeconomic periods. The results demonstrate that the factors are applicable to the Brazilian market, all of which presented statistically significant relationships. In addition, it was possible to observe that periods of crisis affect the relationships verified, indicating a greater sensitivity to risk on the part of investors, especially when analyzing the variables size and level of investment.
\end{abstract}

Keywords: Capital Markets. Asset Pricing. Five Fame and French Factors. Crises. Macroeconomic Periods.

\title{
1 INTRODUÇÃO
}

Fama (1970) propôs o maior avanço à Teoria dos Mercados Eficientes, quando demonstrou que os preços não se movem apenas de maneira aleatória. $O$ autor evidenciou que os preços alteravam quando era divulgada uma nova informação referente a determinado título. Assim, os preços refletiam toda a informação disponível em determinado momento, não sendo possível obter retornos anormais já que os proprietários dos títulos ajustariam seus preços imediatamente na divulgação de novas informações, consequentemente, as próximas transações estariam com seus valores ajustados, impossibilitando especulação pelos investidores. O autor evidenciou ainda que o mercado não atua de maneira totalmente eficiente, assumindo que nem todos envolvidos possuem o mesmo nível de informações existindo diferença entre retorno esperado e observado.

Considerando a ineficiência do mercado, Fama e French $(1992,1993)$ compreenderam que existiria possibilidade de utilizar indicadores e dados históricos para selecionar títulos que pudessem ter maior rentabilidade no futuro. Assim, deram origem ao denominado modelo de três fatores, no qual seria possível construir portfólios através da análise e criação de indicadores baseados no prêmio pelo risco oferecido pelo mercado, em seu tamanho e no indicador B/M (Book-to-market). Este modelo foi aprimorado por Carhart (1997) pela inclusão do fator momento e novamente por Fama e French (2015) com a inclusão de rentabilidade e nível de investimentos compondo o modelo de cinco fatores.

Em seus estudos mais recentes, Fama e French (2015), derivaram a partir do modelo de dividendo descontado, dois novos fatores de risco, a rentabilidade da empresa e nível de investimentos, constituindo assim o modelo de Cinco Fatores de Fama e French. Segundo Vieira et al. (2017), este modelo se constitui na premissa fundamental de que o valor de uma ação no mercado de capitais é determinado através do desconto dos dividendos esperados em exercícios financeiros futuros, uma vez que o valor da ação se origina dos rendimentos repassados pela empresa ao acionista.

Adicionalmente, Oliveira, Silva e Martins (2016) afirmam que as alterações nas condições econômicas, principalmente aquelas relacionadas à evolução de ciclos de negócios do próprio país influenciam os resultados financeiros das empresas e refletem diretamente 
Crises e precificação de ativos no mercado de capitais brasileiro:

Os Cinco Fatores de Fama \& French

no risco de seus títulos. Para eles, os Três Fatores de Fama e French (1993) apresentam comportamento condicional com a evolução da situação econômica do país, ao analisar a zona de moeda única da Europa.

Em âmbito nacional, Bortoluzzo et al. (2016) analisaram três modelos para apreçamento de ativos, o CAPM (capital asset pricing model), o modelo de três fatores de Fama e French (1993) e o de quatro fatores de Carhart (1997), visando verificar o seu poder de previsão, sobretudo em momentos de instabilidade econômica e financeira ocasionados por uma crise internacional. Os autores evidenciaram a existência de relevância destes fatores no mercado de capitais brasileiro (principalmente o tamanho, o índice M/B e o risco), sendo que comportam de maneiras diferentes em períodos de crise, onde se acentua a relevância do risco.

Neste contexto, o presente estudo tem o objetivo principal de identificar como instabilidades econômicas influenciam no comportamento dos Cinco Fatores de Fama e French em relação ao retorno das ações negociadas no mercado de capitais brasileiro.

Para isto, será aplicada uma regressão linear múltipla com dados em painel, utilizando as variáveis componentes do modelo de Cinco Fatores de Fama e French (2015) a uma amostra composta por todas as empresas listadas na Brasil, Bolsa, Balcão (B3), a bolsa de valores oficial do Brasil, no período compreendido 2006 e 2017. Será acrescida ao modelo a divisão de períodos de crise, sendo elas classificadas em pré-crise internacional, crise internacional, póscrise internacional e crise nacional além de um período geral englobando toda a amostra, com o intuito de analisar como os fatores se comportam em relação ao prêmio pelo risco considerando a situação econômica pela qual o país atravessa, bem como as influências de instabilidade financeira em âmbito internacional.

Este estudo se justifica pela necessidade de compreensão do mercado de capitais, pois, segundo a Comissão de Valores Mobiliários (2014), é através dele que é possível o direcionamento da poupança para investimentos produtivos, que beneficia tanto os poupadores, possibilitando melhores retornos do que aplicados em renda fixa, quanto as empresas, que conseguem captar recursos com menor custo de capital. Segundo Sucena e Nami (2011), esta relação possibilita ainda a geração de novos negócios, aumenta a oferta de empregos e contribui para o desenvolvimento do país.

Foram abordados nesta pesquisa temas relevantes para a área de finanças empresariais ao contribuir para a literatura, a partir de pesquisas como de Bortoluzzo et al. (2016), Oliveira, Silva e Martins (2016) e Vieira et al. (2017), através da análise do consagrado modelo de cinco Fatores de Fama e French (2015), seguido da investigação de como ciclos macroeconômicos afetam as relações constatadas na aplicação dos modelos. Por fim, mas não menos importante, este estudo possibilitou a aplicação de todos os conceitos apresentados anteriormente em um país emergente, como é o caso do Brasil, assim, abrangendo um mercado até então pouco explorado pelos pesquisadores.

Desta maneira, o presente artigo se estrutura com a apresentação de cinco sessões, primeiramente, a apresentação de referencial teórico relevante à melhor compreensão sobre o tema estudado, em seguida é apresentada a metodologia com maior grau de detalhamento seguido da apresentação dos resultados obtidos e por fim as considerações finais.

\section{MODELO DE CINCO FATORES DE FAMA E FRENCH}

Apesar do modelo proposto por Fama e French (1993) apresentar poder explicativo consideravelmente superior ao CAPM, diversos autores, como, Haugen e Baker (1996); 
Cohen,Gompers e Vuolteenaho (2002); Fairfield,Whisenant e Yohn (2003); Titman, Wei, e Xie (2004); Fama e French, (2006, 2008) e Novy-Marx (2013) evidenciaram que este modelo é incompleto, uma vez que foram constatadas relações de proxies que dizem respeito à rentabilidade e nível de investimento com o retorno médio dos títulos/portfólios.

Assim, Fama e French (2015) utilizaram o modelo de dividendo descontado para justificar a relação do indicador $\mathrm{B} / \mathrm{M}$ na captação do retorno dos títulos no mercado de capitais, o que se verifica na seguinte equação:

$$
m_{t}=\sum_{\tau=1}^{\infty} E\left(d_{t}+\tau\right) /(1+r)^{\tau}
$$

Na qual, $m_{t}$ representa o preço da ação; $E\left(d_{t}+\tau\right)$ o dividendo esperado para o período e r representando a taxa de retorno esperado para o título a longo prazo.

Relacionando-se a equação (1) com o modelo apresentado por Miller e Modigliani (1961), substituindo os dividendos pela diferença entre a rentabilidade do patrimônio, representado na equação por $Y_{t+\tau}$ e o crescimento (ou redução) do ativo, caracterizando-se pela quantidade de investimentos realizados, representado por $d B_{t+\tau}$, temos:

$$
m_{t}=\sum_{\tau=1}^{\infty} E\left(Y_{t+\tau}-d B_{t+\tau}\right) /(1+r)^{\tau}
$$

Assim, dividindo-se toda a equação pelo valor patrimonial da empresa (B), temos:

$$
\frac{m_{t}}{B_{t}}=\frac{\sum_{\tau=1}^{\infty} E\left(Y_{t+\tau}-d B_{t+\tau}\right) /(1+r)^{\tau}}{B_{t}}
$$

Com base nesta equação, Fama e French (2015), puderam concluir que ao fixar os demais fatores e variar apenas o valor da ação, quanto menor o valor de mercado do título, maior o retorno esperado; com o aumento da rentabilidade da empresa, maior deverá ser o seu retorno esperado e; quanto maiores os investimentos realizados, menor deverá ser o retorno esperado daquele título. Portanto, baseado na constatação matemática da existência de relação entre o indicador $\mathrm{B} / \mathrm{M}$, rentabilidade e nível de investimento de uma empresa com o retorno esperado para os seus títulos, Fama e French (2015) elaboram o modelo de Cinco Fatores, que ganhou a seguinte representação matemática:

$$
R_{i t}-R_{F t}=a_{i}+b_{i}\left(R_{M t}-R_{F t}\right)+s_{i} S M B_{t}+h_{i} H M L_{t}+r_{i} R M W_{t}+C_{i} C M A_{t}+e_{i t}(4)
$$

Na qual:

$\mathrm{R}_{\mathrm{it}}=$ retorno médio do portfólio i no tempo t;

$\mathrm{R}_{\mathrm{Ft}}=$ taxa livre de risco;

$\mathrm{R}_{\mathrm{Mt}}$ = indicador de mercado;

$\mathrm{SMB}=$ tamanho das empresas;

$\mathrm{HML}=$ valor das empresas;

$\mathrm{RMW}=$ rentabilidade das empresas;

CMA = nível de investimento;

$a_{i}=$ intercepto da regressão, também chamado de alfa de Jensen; e

$\mathrm{e}_{\mathrm{it}}=$ termo de erro da regressão.

Fama e French (2015, 2016 e 2017) testaram o Modelo de Cinco Fatores e evidenciaram que existem padrões relacionando o tamanho, $\mathrm{B} / \mathrm{M}$, rentabilidade $\mathrm{e}$ investimento ao retorno esperado das ações. Eles verificaram ainda que firmas lucrativas e com investimento conservador captam altos retornos médios associados a baixo beta de mercado, recompra de ações e baixa volatilidade. Assim, os autores validaram o modelo para 
Crises e precificação de ativos no mercado de capitais brasileiro:

Os Cinco Fatores de Fama \& French

a América do Norte, Europa, região da Ásia-Pacífico, exceção feita ao Japão, onde não houve evidências de relação para a rentabilidade e investimento.

Chiah et al. (2016), na Austrália e Lin (2017), na China, analisaram a aplicação do Modelo de Cinco Fatores e verificaram que este possibilitou maior poder explicativo do que o modelo de três fatores e com a inclusão do fator momento. Os pesquisadores evidenciaram a relevância dos fatores valor e rentabilidade. Adicionalmente, Guo et al. (2017), revelaram a relação para o fator tamanho no mercado chinês. Resultados estes diversos dos de Kubota e Takehara (2018) para o mercado japonês.

No mercado brasileiro, Machado, Faff e Silva (2017) investigaram se os fatores adicionados mais recentemente por Fama e French (2015) ao modelo de cinco fatores explicam o retorno das ações. Os autores constataram que investimento e rentabilidade não apresentam relações estatisticamente significantes, no entanto, que os fatores $B / M$, momento e liquidez possuem relações estatisticamente comprovadas com o retorno das ações, desta maneira, constatando que o modelo de cinco fatores de Keene e Peterson (2007) apresentaram melhores resultados para o mercado de capitais brasileiro.

Ainda em relação a estudos nacionais, Vieira et al. (2017) aplicaram o modelo de cinco fatores de Fama e French (2015) em uma amostra composta pelas empresas listadas na B3, no período compreendido entre 2008 e 2015, as quais foram divididas em cinco setores (materiais básicos, consumo cíclico, consumo não cíclico, industrial e utilidade pública. Os resultados obtidos pelos autores indicam que a variável de prêmio de risco do mercado foi estatisticamente significante em todos os setores analisados. Identificaram ainda a importância do fator investimento, que se mostrou significativo em três dos cinco setores analisados, no entanto, com relação diversa daquela indicada por Fama e French (2015) em dois deles.

Portanto, observa-se que não existe um consenso sobre quais os melhores modelos ou sobre a aplicação adequada de cada um deles. Além disto, destaca-se também que o modelo de cinco fatores proposto por Fama e French (2015) ainda não foi estudado levando em consideração a alteração sofrida pelos fatores ao longo do tempo, sobretudo em momentos de crise, conforme proposto por Bortoluzzo et al. (2016), desta maneira, identificando a lacuna na literatura na qual esta pesquisa busca preencher.

\subsection{AS CONSEQUÊNCIAS DAS CRISES NO MERCADO DE CAPITAIS}

Sallaberry e Medeiros (2015) apontam que no período de 2003 a 2007, o valor de mercado das empresas listadas na B3 obteve um aumento superior a $\mathrm{R} \$ 2$ trilhões e neste mesmo período, Peixoto (2012) revela que o mercado de capitais e as indústrias brasileiras operavam em um ambiente de liquidez, crescimento no valor das ações e expansão na produção e no consumo, caracterizando um período de estabilidade econômica e de expansão do mercado de capitais brasileiro.

Gonçalves Junior e Eid Junior (2016) afirmam que as expectativas de crescimento do país motivam os investidores estrangeiros a intensificar seu volume tanto de compra quanto de vendas no mercado de capitais brasileiro. Para Stulz (1999), este incremento de investimentos estrangeiros aumenta a demanda pelos títulos, levando à valorização das empresas, e como consequência, estas empresas tendem a priorizar a captação no mercado de capitais, com custos menores, estimulando o crescimento da economia do país.

Por outro lado, segundo Peixoto (2012), a crise global de 2008 desvalorizou em quase $45 \%$ as empresas nacionais listadas na $B 3$, passando de um valor de $R \$ 2,47$ trilhões para $R \$$ 
1,37 trilhões. Aldrighi e Cardoso (2009) revelam que os grandes investidores estrangeiros expostos a riscos em países emergentes tendem a liquidar suas posições, aumentando sua liquidez e reduzindo riscos, o que ocasiona o efeito manada, uma vez que devido à assimetria de informações, ao perceberem o grande volume de vendas de determinado ativo, outros investidores tendem a gerar uma onda de ordens de venda, visando a encerrar suas posições em papéis similares, deprimindo os preços do mercado de uma forma geral.

Iniciado o efeito manada, os grandes fundos seguem a tendência do mercado, mesmo que entendam que a queda esteja em desacordo com os fundamentos das empresas, para evitar problemas de agência, pois os gestores se veem em uma situação na qual é melhor errar seguindo o mercado, e consequentemente reduzir sua remuneração, do que manter sua posição e sofrer com a desvalorização dos títulos isolado no mercado, o que possivelmente ocasionaria demissão deste gestor. Peixoto (2012) complementa argumentando que esta evasão potencializou a queda no mercado acionário brasileiro pela redução da demanda e nos preços das commodities.

Ainda nos dois primeiros trimestres de 2009, conforme apontado por Sallaberry e Medeiros (2015), o valor de mercado das empresas listadas na B3 foi parcialmente recomposto e manteve-se relativamente estável com tendência de baixa nos períodos subsequentes. Além disto, Peixoto (2012) afirma que o volume de crédito se elevou e que em 2010 o PIB apresentou aumento em relação ao período anterior, indicando que já se havia a partir de 2009 uma recuperação econômica consistente.

Apesar da recuperação do mercado de capitais, Cagnin et al. (2013) apontam que a partir de 2012, houve uma convergência de fatores, tais como o enfraquecimento da demanda externa, como resquício da crise do subprime e da recessão na Europa, o acirramento da economia internacional, o atingimento dos limites da estratégia de estímulo da demanda por parte do governo, desvalorização cambial, incertezas quanto às ações políticas do país e a evolução dos preços.

Por sua vez, o risco das aplicações no mercado de capitais brasileiro aumentou, afastando novamente os investidores estrangeiros, situação agravada pela deflagração da operação Lava Jato, que conduziu inicialmente a investigações de irregularidades em relação à contratação de obras superfaturadas, mediante pagamento de propina a agentes públicos e políticos, as quais causavam grande desvio de recursos da maior empresa listada no mercado de capitais brasileiro. Com a credibilidade abalada, esta sinergia de fatores levou à queda gradual da Bolsa de Valores, a partir do ano de 2012, partindo dos 60.952 pontos até a sua menor cotação verificada pelo período em análise, quando atingiu 37.497 pontos em janeiro de 2016. Caracterizando assim, um período de recessão nacional, inaugurada a partir do ano de 2012, que impactou diretamente na queda do mercado de capitais.

Portanto, diante dos fatos apresentados e de acordo com Garcia e Ghysels (1998) e Bortoluzzo et al. (2016), faz-se importante estudar as mudanças nos mercados, sobretudo quando há quebras estruturais nas séries temporais advindas de períodos de crise, uma vez que a estrutura de correlação entre os fatores sofre alteração ao longo do tempo.

\subsection{HIPÓTESES DE ESTUDO}

Ao sugerir a substituição do modelo de três fatores pelo de cinco fatores, Fama e French (2015) evidenciaram a existência de relação das variáveis rentabilidade e nível de investimentos com o retorno esperado pelas ações negociadas em bolsas de valores. Desta maneira, inicialmente, este estudo verificou se estes novos fatores apresentam para o mercado de capitais brasileiro a mesma relação indicada pelos autores, de maneira geral, para 
Crises e precificação de ativos no mercado de capitais brasileiro:

Os Cinco Fatores de Fama \& French

a partir deste ponto, analisar como os períodos de crise afetam os resultados apontados pelas variáveis presentes no modelo.

Ao tratar da variável rentabilidade, Fama e French (2015) afirmam que empresas com rentabilidade robusta possuem maior capacidade de distribuição de dividendos, implicando na elevação do valor de mercado da organização, e consequentemente na variação positiva do retorno dos seus títulos. Maior rentabilidade indica a existência de bons resultados, tornando-se atraente aos investidores que buscam por aplicações mais seguras. Assim, quanto maior a rentabilidade, maiores devem ser os retornos das ações.

Novy-Marx (2013) obteve resultado semelhante, ao constatar que empresas mais rentáveis apresentam retorno dos seus títulos significativamente maiores e que esta rentabilidade apresenta associação com crescimento na receita, lucro, fluxo de caixa e dividendos, além de possuírem maior perenidade.

Assim, com relação ao indicador rentabilidade, foi elaborada a hipótese a seguir:

$\mathbf{H}_{1}$ : Há relação positiva entre a rentabilidade das empresas e o retorno das ações.

Segundo Fama e French (2015), empresas que realizam menores volumes de investimentos elevam o caixa, desta maneira, distribuindo maiores montantes de dividendos, elevando os preços dos seus títulos, possibilitando o retorno em curto prazo aos acionistas. Assim, quanto menores os investimentos realizados por uma organização, maiores devem ser o retorno de seus títulos.

No mercado de capitais brasileiro, Vieira et al. (2017) constataram a mesma relação proposta por Fama e French (2015), uma vez que, os níveis de investimento foram estatisticamente significantes e negativos para dois de três setores dos quais foi possível identificar a relação deste fator com o retorno das ações. Os autores completam afirmando que nem sempre um acréscimo nos investimentos impacta positivamente a performance da empresa. Portanto, desta relação, foi elaborada a hipótese $\mathrm{H} 2$ :

$\mathbf{H}_{\mathbf{2}}$ : Há relação negativa entre nível de investimento e o retorno das ações.

Verificada a aplicabilidade do modelo de cinco fatores ao mercado brasileiro, mediante análise das variáveis rentabilidade e nível de investimento, o estudo partiu para análise das alterações verificadas nos períodos classificados como crise.

Em momentos de crise, as empresas que ainda não estão consolidadas no mercado e que possuem menor capacidade tanto estrutural quanto financeira tornam-se investimentos mais arriscados, perdendo liquidez e valor, assim, espera-se que empresas de maior porte tenham maior capacidade de manter os bons resultados operacionais, gerando maior retorno aos acionistas, contrariando o efeito tamanho proposto por Banz (1981).

Vieira et al. (2017), discorre ainda que a relação negativa entre o tamanho das empresas e o retorno de suas ações se dá pela dificuldade em transpor barreiras de entrada nos setores que dispõe de alta exigência de regulação legal, como de utilidade pública. Os autores argumentam também que o processo de produção pode se constituir como uma barreira de entrada aos empreendimentos de menor porte, uma vez que não se conseguem atingir as economias de escala daqueles de maior tamanho e mais bem posicionadas no mercado de atuação.

Jensen, Johnson e Mercer (1996, 1997), L’Her et al. (2004) e Oliveira, Silva e Martins (2016) também constataram que a situação econômica do país influencia nos fatores de risco e a variável tamanho foi aquela que se apresentou significante em todos estes estudos mencionados. Diante do exposto, foi elaborada a hipótese $\mathrm{H}_{3}$, a seguir: 
Kleverson Dáliton Silva Moreira, Antonio Sergio Torres Penedo, Vinicius Silva Pereira e Marcelo Augusto Ambrozini

$\mathbf{H}_{3}$ : Em momentos de instabilidade econômica (Crise Internacional e Recessão Nacional), há uma relação positiva para o fator tamanho e o retorno das ações.

De acordo com Lin (2017), em países emergentes, existe grande proximidade entre os valores de rentabilidade e investimento das empresas componentes do mercado de capitais, tornando a margem de distribuição de dividendos cada vez menor. Soma-se a isto o fato de que no Brasil, os dividendos agem como forma de proteção ao acionista, como proposto por La Porta et al. (2000), baseada em exigências legais, pela estipulação de valores mínimos. Neste contexto, os investidores esperam pela valorização de seus títulos pelo ganho de valor das ações possibilitado pelo incremento no nível de investimentos.

Vieira et al. (2017), afirmam ainda que a capacidade de explicação do fator investimento em relação ao prêmio de risco obtido através da valorização das ações mostra aos gestores a importância em refletir sobre a política de investimento devido ao seu impacto no resultado. Assim, espera-se que em momentos de instabilidade econômica e/ou financeira, os acionistas tenham preferência pelo recebimento de dividendos em detrimento à realização de investimentos, dada a imprevisibilidade de retorno que podem ser gerados ao investir nos projetos apresentados pela empresa em ambientes instáveis. Desta relação, originou-se a $\mathrm{H}_{4}$ :

$\mathbf{H}_{4}$ : Em momentos de instabilidade econômica (Crise Internacional e Recessão Nacional), há uma relação positiva para o fator nível de investimento e o retorno das ações.

\section{METODOLOGIA}

A amostra desta pesquisa foi composta por todas as empresas listadas na B3 no período compreendido entre 2006 e 2017, permitindo recortes quanto à situação econômica, distinguindo período geral, composto pela amostra completa, e outros quatro períodos distintos, sendo eles: pré-crise internacional, crise internacional, pós-crise internacional e recessão nacional.

Para isto, foi consultada a base de dados Economatica, e aplicou-se filtro para exclusão de empresas do setor financeiro, justificado por Bortoluzzo et al. (2016) afirmando que estas podem distorcer os efeitos analíticos da variável $B / M$, uma vez que apresentam endividamento superior aos demais setores. Adicionalmente, as ações que possuem mais de um tipo de negociação tiveram seu título menos líquido excluído. Desta maneira, foram extraídos os dados de um total de 688 empresas componentes da base de dados formada. Considerando que ao aplicar os modelos de regressão, as empresas com dados incompletos são eliminadas da análise, a amostra média para cada modelo foi de 264 empresas.

Na sequência, foram aplicadas as variáveis propostas por Fama e French (2015), sendo elas o tamanho da empresa, seu valor patrimonial em relação ao valor de mercado, o fator risco, bem como as variáveis adicionadas no último modelo proposto pelos autores, sendo elas a rentabilidade e o nível de investimento.

Diante do exposto, tem-se que a variável dependente deste estudo, de forma similar ao estudo de Fama e French (1993), é o retorno médio das ações ajustado ao risco, representado aqui como RET, que é calculado levando em consideração a variação percentual do preço de fechamento da ação em comparação ao encerramento do ano anterior e subtraído pelo ativo livre de risco, neste caso sendo representada pelo retorno da taxa SELIC embasada nos estudos de Faria et al. (2011), Matos e Rocha (2009), nCastro e Minardi (2009) e Bergmann et al. (2014), os quais expõem que tal variável condiz com a teoria do CAPM, a qual serviu de base para o modelo de três fatores de Fama e French. 
Crises e precificação de ativos no mercado de capitais brasileiro:

Os Cinco Fatores de Fama \& French

A opção pela utilização da SELIC como taxa livre de risco, em detrimento da poupança, como utilizada nos estudos de Málaga (2005), Rogers e Securatto (2009) e Bortoluzzo et al. (2016), se justifica ao considerar a mudança nas regras de rendimento da poupança inviabilizando sua utilização, devido à forma de cálculo do rendimento de maneiras diferentes durante o período de 2006 a 2017.

Dando início na apresentação das variáveis independentes, o primeiro fator se constitui no Prêmio de Mercado, tal como utilizado em Fama e French (1993). Neste estudo, utilizou-se o beta do título em relação ao mercado como proxy de risco, tal como aplicado no estudo de Serra e Martelanc (2016), uma vez que os títulos não foram dispostos em carteiras. Esta variável, aqui denominada como RISC, indica como o rendimento daquele título específico se comporta em relação ao mercado como um todo, assim, deixando clara a relação entre risco e retorno. Espera-se a obtenção de uma relação positiva, indicando que quanto maior o risco assumido ao investir em determinado título, maior é o retorno exigido.

A segunda variável independente, retratada por TAM (tamanho), representa o tamanho das empresas componentes da amostra. Segundo Fama e French (1993), bem como Bortoluzzo et al. (2016), espera-se um sinal negativo em condições de estabilidade econômica, no entanto, um sinal positivo nos períodos de crise, uma vez que nesta ocasião as empresas de menor porte aparecem como mais arriscadas e consequentemente perdem liquidez e valor.

A última variável constante no modelo original dos Três Fatores de Fama e French (1993) representada pela sigla VAL (valor), indica a relação entre valor de mercado e valor patrimonial das empresas e é através dela que surgiu a categorização de títulos de valor e de crescimento, no qual, segundo Brealey, Mayers e Allen (2011), ações de valor (representadas por aquelas com maiores indicadores $\mathrm{B} / \mathrm{M}$ ) proporcionam maiores retornos a longo prazo. Ao se considerar o retorno histórico das ações listadas na Bolsa de Valores de Nova York, desde 1926, as ações de valor apresentaram retorno médio anual de 5,2\% a mais que as ações de crescimento. Portanto, para esta variável, espera-se uma relação positiva, indicando que quanto maior o indicador $\mathrm{B} / \mathrm{M}$ maiores serão os retornos observados pelos títulos destas empresas.

As variáveis seguintes são aquelas que modificaram o modelo de três fatores para comporem os cinco fatores, e fazem referência à rentabilidade e nível de investimento das organizações. Fama e French (2015) justificam a inserção destas variáveis ao modelo expondo que a variável $\mathrm{B} / \mathrm{M}$ é uma proxy ruidosa do retorno das ações e que pode haver ganhos na explicação dos retornos ao inserir rentabilidade e nível de investimento, uma vez que estas possuem fortes relações com a capitalização de mercado das organizações.

A rentabilidade, aqui representada por RENT, visa demonstrar a relação entre o resultado operacional das empresas com seu retorno médio e foi calculada pela divisão do EBITDA pelo Ativo Total, demonstrando o quanto os ativos da organização geraram de rentabilidade naquele período. Segundo Fama e French (2015), as empresas que obtém maiores indicadores nestas variáveis atraem maior atenção dos acionistas, gerando maior retorno.

Por fim, a última variável independente é o nível de investimento das empresas (INV) e representa a variação do capital próprio em determinado período. Segundo Fama e French (2015), um aumento desta variável acarreta menor ganho para o investidor na forma de dividendos, impactando negativamente no retorno das ações.

O Quadro 1 traz um resumo de todas as variáveis pertencentes a este estudo, bem como sua forma e mensuração e autores que as utilizaram anteriormente. 
Kleverson Dáliton Silva Moreira, Antonio Sergio Torres Penedo, Vinicius Silva Pereira e Marcelo Augusto Ambrozini

Quadro 1 - Classificação das Variáveis

\begin{tabular}{|c|c|c|c|c|c|}
\hline Variável & $\begin{array}{l}\text { Tipo de } \\
\text { Variável }^{b}\end{array}$ & Sigla & Forma de Mensuração ${ }^{c}$ & Fonte & Autores $^{a}$ \\
\hline Retorno & VD & RET & $\left.\left(\frac{\left(\operatorname{Ret}_{\text {fim }(\%)}-\operatorname{Ret}_{\text {ini }(\%)}\right)}{\operatorname{Ret}_{\text {ini }(\%)}}-S E L I C(\%)\right)\right|_{100}$ & $\begin{array}{l}\text { Economatica } \\
\text { / Banco } \\
\text { Central }\end{array}$ & $\begin{array}{l}(1),(2) \\
(3),(4) \mathrm{e} \\
(5)\end{array}$ \\
\hline Risco $(\beta)$ & VI & RISC & $\frac{\operatorname{Cov}\left(r_{a}, r_{m}\right)}{\operatorname{Var}\left(r_{m}\right)}$ & Economatica & (6) \\
\hline $\begin{array}{l}\text { Porte da } \\
\text { Empresa }\end{array}$ & VI & TAM & Logaritmo natural de Ativos & Economatica & (1) e (7) \\
\hline Valor & VI & VAL & $\frac{(\text { Ativo Total }- \text { Passico Circulante }-E L P)}{\text { Valor de Mercado }}$ & Economatica & $\begin{array}{l}(1),(6) \mathrm{e} \\
(7)\end{array}$ \\
\hline Rentabilidade & VI & RENT & $\frac{\text { EBITDA }}{\text { Ativo Total }}$ & Economatica & $\begin{array}{l}\text { (8), (9) e } \\
(10)\end{array}$ \\
\hline $\begin{array}{c}\text { Nível de } \\
\text { Investimentos }\end{array}$ & VI & INV & $\frac{\left(\text { Ativo }_{\text {fim }(\%)}-\text { Ativo }_{\text {ini }(\%)}\right)}{A \operatorname{tivo}} /_{\text {ini }(\%)} / 100$ & Economatica & $\begin{array}{l}\text { (8), (9) e } \\
(10)\end{array}$ \\
\hline
\end{tabular}

(a): (1) Fama e French (1993); (2) Faria et al. (2011); (3) Matos e Rocha (2009); (4) Castro e Minardi (2009); (5) Bergmann et al. (2014); (6) Serra e Martelanc (2016); (7) Bortoluzzo et al. (2016); (8) Fama e French (2015, 2016, 2017); (9) Kubota e Takehara (2018); (10) Lin (2017). (b): VD = Variável Dependente; VI = Variável Independente; VC = Variável de Controle. (c): Ret = Retorno; SELIC= Sistema Especial de Liquidação e Custódia; Cov = covariância; Var = variância; ELP = Exigível a Longo Prazo; EBITDA = Lucros antes de juros, impostos, depreciação e amortização.

Fonte: elaborado pelos autores (2019).

O Quadro 2 traz um resumo dos sinais esperados para cada variável, bem como uma breve explicação do seu significado, visando a uma melhor compreensão dos resultados que serão apresentados na próxima sessão.

Quadro 2 - Sinais esperados para cada variável e explicação

\begin{tabular}{|c|c|l|}
\hline Variável & Sinal Esperado & \multicolumn{1}{c|}{ Explicação da relação } \\
\hline RISC & + & Quanto maior o risco do título, maior deverá ser o seu retorno. \\
\hline TAM & - & $\begin{array}{l}\text { Segundo o efeito tamanho, proposto por Banz (1981), quanto menor a } \\
\text { empresa, maior deverá ser o retorno de sua ação. }\end{array}$ \\
\hline VAL & + & $\begin{array}{l}\text { Títulos de empresas classificados como de valor (maior indicador B/M) } \\
\text { apresentam maior retorno ajustado ao risco. }\end{array}$ \\
\hline RENT & + & $\begin{array}{l}\text { Quanto maior a rentabilidade de uma empresa, maior a probabilidade } \\
\text { de distribuição de dividendos, consequentemente, maior valorização } \\
\text { dos títulos. }\end{array}$ \\
\hline INV & - & $\begin{array}{l}\text { Quanto menos recursos foram utilizados para investimento, maiores } \\
\text { serão os recursos disponíveis aos acionistas. }\end{array}$ \\
\hline
\end{tabular}

Fonte: elaborado pelos autores (2019).

Bortoluzzo et al. (2016) evidenciaram ainda que instabilidade econômico-financeira, tais como a crise de 2008 nos Estados Unidos, podem afetar a estrutura de relação dos ativos de risco e que, portanto, é imprescindível conhecer como se dão estas mutações no mercado de capitais para a manutenção da capacidade preditiva dos modelos econométricos.

Em sequência ao estudo de Fama e French (2015) e Bortoluzzo et al. (2016), com as variáveis expostas, este trabalho possui o objetivo de segregar os períodos em crise financeira internacional, crise nacional e estabilidade econômica, identificando quais variáveis ganham relevância em cada um dos períodos mencionados, bem como avançar na compreensão de como momentos de instabilidade afetam o mercado acionário brasileiro. 
Crises e precificação de ativos no mercado de capitais brasileiro:

Os Cinco Fatores de Fama \& French

Para isto, será seguido o mesmo critério desenvolvido por Santos e Montezano (2011), o qual considera períodos de crises aqueles nos quais houve variação percentual negativa do índice Bovespa (IBOVESPA). Portanto, este estudo considerou os anos de 2006 e 2007 como período pré-crise internacional; 2008 e 2009 como crise internacional; 2010 e 2011 como período pós-crise internacional; e os anos de 2012, 2013, 2014, 2015, 2016 e 2017 como crise doméstica. Assim, espera-se que haja uma mudança na relação existente entre as variáveis independentes e o retorno das ações ao se considerar a existência de crise, como evidenciado em Bortoluzzo et al. (2016).

Desta maneira, visando à determinação dos fatores que apresentam relação com o retorno anormal das ações, foram utilizadas cinco regressões múltiplas com dados em painel, pela aplicação das variáveis propostas no Modelo de Cinco Fatores de Fama e French (2015) e os períodos segmentados conforme Bortoluzzo et al. (2016), com o acréscimo de um período denominado crise nacional, possibilitando a verificação de como a situação econômica se relaciona com o retorno das ações brasileiras, mediante a aplicação do modelo econométrico exibido na Equação 5.

$$
R E T_{i t}=\alpha+\beta_{1} \mathrm{RISC}_{\mathrm{it}}+\beta_{2} \mathrm{TAM}_{\mathrm{it}}+\beta_{3} \mathrm{VAL}_{\mathrm{it}}+\beta_{4} \mathrm{RENT}_{\mathrm{it}}+\beta_{5} \mathrm{INV}_{\mathrm{it}}+\varepsilon i(5)
$$

Onde:

$\mathrm{RET}_{\text {it: }}$ retorno médio anual do título i no tempo t subtraído da taxa livre de risco (SELIC) no tempo t;

RISC it: risco do título i no tempo t, medido pelo beta de mercado;

TAMit:representa o tamanho das empresas;

VAL ${ }_{i t}$ : indicador relacionado ao valor das empresas, baseado na relação $B / M$;

RENT $_{\text {it: }}$ rentabilidade do ativo total da empresa i no tempo t;

INV it: variação do nível de valores investidos da empresa i em relação ao tempo t-1;

$\alpha_{i}$ : intercepto da regressão;

$\varepsilon$ : termo de erro da regressão.

Para o tratamento dos dados e geração de tabelas e gráficos expostos na sessão de resultados foi utilizado o software Stata, em sua versão 13.

\section{ANÁLISE DOS RESULTADOS}

\subsection{Análise Descritiva}

Iniciando a discussão dos resultados, primeiramente a Tabela 1 mostra as estatísticas descritivas das variáveis de estudo.

Tabela 1 - Estatísticas descritivas das variáveis

\begin{tabular}{|c|c|c|c|c|c|c|c|c|c|c|}
\hline \multirow[b]{2}{*}{ Variável } & \multicolumn{2}{|c|}{ Geral } & \multicolumn{2}{|c|}{$\begin{array}{c}\text { Pré-Crise } \\
\text { Internacional }\end{array}$} & \multicolumn{2}{|c|}{$\begin{array}{c}\text { Crise } \\
\text { Internacional }\end{array}$} & \multicolumn{2}{|c|}{$\begin{array}{c}\text { Pós-crise } \\
\text { Internacional }\end{array}$} & \multicolumn{2}{|c|}{$\begin{array}{l}\text { Recessão } \\
\text { Nacional }\end{array}$} \\
\hline & Obs. & Média & Obs. & Média & Obs. & Média & Obs. & Média & Obs. & Média \\
\hline RET & 2995 & $-0,0131$ & 412 & 0,3524 & 529 & 0,0226 & 527 & $-0,1250$ & 1527 & $-0,0856$ \\
\hline RISC & 2874 & 0,6529 & 385 & 0,6191 & 516 & 0,8437 & 508 & 0,4531 & 1465 & 0,6638 \\
\hline TAM & 4693 & 20,8155 & 826 & 20,5663 & 814 & 20,7771 & 803 & 20,9400 & 2250 & 20,8764 \\
\hline VAL & 3433 & 0,6787 & 572 & 0,4555 & 597 & 0,6485 & 598 & 0,6560 & 1666 & 0,7741 \\
\hline RENT & 4311 & 0,0680 & 768 & 0,0754 & 737 & 0,0811 & 712 & 0,0769 & 2094 & 0,0576 \\
\hline
\end{tabular}


Kleverson Dáliton Silva Moreira, Antonio Sergio Torres Penedo, Vinicius Silva Pereira e Marcelo Augusto Ambrozini

\begin{tabular}{l|llllllllll} 
INV & 4548 & 0,0407 & 763 & 0,0856 & 793 & 0,0647 & 780 & 0,0993 & 2212 & $-0,0040$
\end{tabular}

Fonte: elaborado pelos autores (2019) com base nos resultados da pesquisa.

Ao observar a Tabela 1, nota-se que os períodos macroeconômicos de crise implicam em oscilações nos valores das variáveis, tal como a rentabilidade dos títulos, que apesar de ser negativa na amostra como um todo, apresentou resultados positivos em períodos específicos, sobretudo, naquele que antecedeu a crise internacional.

Observa-se ainda que os títulos se tornaram mais arriscados nos períodos de Crise Internacional e de Recessão Nacional, o que condiz com a teoria, uma vez que nos períodos de instabilidade os investidores têm maior dificuldade em prever os resultados das organizações, desta maneira, sendo mais viável a venda de títulos de empresas não muito consolidadas.

Quanto ao fator valor, é visível que no período que antecedeu a crise internacional as empresas apresentavam indicador $\mathrm{B} / \mathrm{M}$ em patamares mais baixos do que no restante dos períodos, indicando que os títulos estavam supervalorizados naquele momento, devido ao grande volume de capital investido no mercado, levando os preços dos títulos a patamares irracionais, devido à alta demanda. Nos períodos subsequentes, é evidenciado que o mercado passou a valorizar de maneira mais racional os títulos negociados, talvez este comportamento tenha sido adquirido pela experiência de ter passado por momentos de dificuldade, contribuindo para um amadurecimento do mercado.

Quanto à rentabilidade das organizações, observou-se que a recessão nacional afetou mais fortemente a produção das empresas, sendo que este foi o período que apresentou os menores resultados. $\mathrm{O}$ fator nível de investimentos apresentou comportamento similar, no entanto, ambos os períodos de crise afetaram negativamente a quantidade de investimentos realizados pelas empresas, deixando claro o contraste dos períodos de pré e pós-crise, em relação aos períodos de crise e recessão.

\subsection{Análise das regressões}

Dando prosseguimento às análises, antes de serem apresentados os resultados das regressões foram realizados testes para verificação do atendimento aos pressupostos estatísticos dos dados e existência de outliers, a qual foi constatada, por este motivo, foi realizada uma winsorização dos dados até o limite de 0,2 , visando a eliminar tal problema. $\mathrm{Na}$ sequência, foi aplicado o modelo econométrico apresentado na Equação 5.

Foram realizadas cinco regressões com dados em painel pela aplicação da Equação 5. A regressão do período Geral representa todo o período analisado (2006 a 2017), o período de Pré-crise faz referência aos anos de 2006 e 2007, Crise Internacional representa os anos de 2008 e 2009, Pós-crise Internacional considerou os anos de 2010 e 2011, por fim, caracterizouse como Recessão Nacional o período de 2012 a 2017. Os testes VIF indicaram não existir problema de multicolineraridade, uma vez que observou-se valores médios abaixo de 10 . Os testes de Breusch-Pagan, de Chow e de Hausman indicaram que o modelo de efeitos fixos é o mais adequado e foi aplicado em todas as regressões deste estudo. Os resultados obtidos podem ser verificados na Tabela 2. 
Crises e precificação de ativos no mercado de capitais brasileiro:

Os Cinco Fatores de Fama \& French

Tabela 2 - Resultados das Regressões com dados em painel

\begin{tabular}{lccccc}
\hline & Geral & Pré-crise & $\begin{array}{c}\text { Crise } \\
\text { Internacional }\end{array}$ & $\begin{array}{c}\text { Pós-crise } \\
\text { Internacional }\end{array}$ & $\begin{array}{c}\text { Recessão } \\
\text { Nacional }\end{array}$ \\
\hline Empresas & 352 & 206 & 240 & 245 & 276 \\
consideradas & & & & & \\
no Obs. & 2622 & 352 & 445 & 451 & 1374 \\
VIF & 1,13 & 1,15 & 1,16 & 1,14 & 1,16 \\
$\mathrm{R}^{2}$ & 0,0572 & 0,0674 & 0,0555 & 0,0139 & 0,0457 \\
\hline Breusch-Pagan & 0,0000 & 0,4292 & 0,0000 & 0,2886 & 0,0000 \\
Chow & 0,0132 & 0,0008 & 0,0031 & 0,0052 & 0,0297 \\
Hausman & 0,0000 & 0,0000 & 0,0000 & 0,0000 & 0,0000 \\
\hline \multicolumn{1}{c}{ Variáveis } & & & Coeficientes & & \\
\hline \multicolumn{1}{c}{ RISC } & $0,0395^{* *}$ & 0,0197 & $-0,1311$ & $-0,0008$ & $0,0974^{* * *}$ \\
$\quad$ TAM & $-0,0594^{* *}$ & $-0,2839$ & $1,1582^{* * *}$ & $-0,9121^{* * *}$ & $-0,0943^{* *}$ \\
$\quad$ VAL & $-0,3218^{* * *}$ & $-0,8765^{* * *}$ & $-1,6819^{* * *}$ & $-0,3663^{* * *}$ & $-0,2633^{* * *}$ \\
$\quad$ RENT & $1,0534^{* * *}$ & 0,4573 & $1,2066^{*}$ & $1,2868^{* * *}$ & $1,3567^{* * *}$ \\
$\quad$ INV & $0,1525^{* *}$ & $0,8100^{* *}$ & $-1,2402^{* * *}$ & $0,9458^{* * *}$ & $0,3246^{* * *}$ \\
\multicolumn{1}{c}{ Constante } & $1,3885^{* *}$ & 6,7518 & $-23,6768^{* * *}$ & $19,7977^{* * *}$ & $2,0198^{* *}$ \\
\hline
\end{tabular}

Os asteriscos $*, * *$ e ${ }^{* * *}$, representam significância aos níveis de $10 \%, 5 \%$ e $1 \%$ respectivamente. Variáveis: RISC - Risco; TAM - Tamanho; VAL - Valor; RENT - Rentabilidade; INV - Investimento.

Fonte: elaborado pelos autores (2019) com base nos resultados da pesquisa.

De acordo com os dados expostos na Tabela 2, verifica-se que a amostra média para cada regressão foi de 264 empresas, variando de 206 para o período com menor quantidade e 352 para o de maior número de observações. Verifica-se também que, de maneira geral, todas as variáveis do estudo apresentaram relação estatisticamente significante com o retorno ajustado ao risco dos títulos analisados, sendo positivo para as variáveis RISC, RENT e INV e negativa para as variáveis TAM E VAL.

Observa-se também que todas as variáveis de estudo foram estatisticamente significantes ao explicar o retorno em excesso das ações nos períodos geral e recessão nacional. Nos períodos de Crise Internacional e pós-crise, apenas o fator risco de mercado não apresentou significância estatística.

Por outro lado, no período denominado Pré-crise Internacional, apenas as variáveis VAL e INV mantiveram seu poder explicativo. Esta constatação pode significar que devido ao ambiente favorável, no qual se havia uma expansão geral no mercado, não havia necessidade de se fazer análises fundamentalistas complexas para investir em títulos rentáveis. Gonçalves Junior e Eid Junior (2016) esclarecem no momento de estabilidade pré-crise, o país atraia grande volume de investimentos estrangeiros, que buscavam aplicar os recursos em empresas que apresentassem projetos com potencial de elevar seu valor de mercado, assim, incentivando a aquisição de ativos por quase todos os tipos de empreendimentos.

O parâmetro alfa (constante), apresentou-se estatisticamente significante em quatro das cinco regressões realizadas, o que indica a possibilidade de existência de fatores não fundamentalistas que afetaram os retornos deste período, evidências estas, de acordo com Shiller (2003), o qual expõe que os investidores nem sempre são racionais e podem tomar decisões baseadas na psicologia e na sociologia, tal como simplesmente operar pela influência do efeito manada, ocasionado pelas crises, desconsiderando desta maneira os resultados reais apresentados pelas organizações. 
Kleverson Dáliton Silva Moreira, Antonio Sergio Torres Penedo, Vinicius Silva Pereira e Marcelo Augusto Ambrozini

As relações verificadas por cada um dos fatores e a discussão sobre estes resultados serão apresentados com maior detalhamento no tópico a seguir.

\subsection{Discussão dos resultados}

Tratando-se inicialmente da aplicação dos cinco fatores de Fama e French (2015) a toda a amostra disponível, considerando o período de 2005 a 2016, os resultados gerais apontam que o beta do título (variável risco de mercado) influencia diretamente e no mesmo sentido o retorno das ações, assim, quanto mais arriscado for um título, maior deverá ser o seu retorno exigido por parte dos investidores, estando desta maneira de acordo com Markowitz (1952) e com a teoria do CAPM, no entanto, não sendo o único fator explicativo do retorno das ações, em conformidade com o já exposto por Fama e French (1992, 1993 e 2015).

Quanto ao tamanho, evidencia-se que quanto menor o porte da empresa, maiores são os seus retornos ajustados ao risco, de acordo com os resultados evidenciados por Fama e French (2015) e Oliveira, Silva e Martins (2016), os quais explicam que este fato se dá pelo motivo de empresas de menores dimensões apresentarem maiores riscos e também menor possibilidade de diversificação eficientes, desta maneira, havendo a necessidade de propiciar maiores retornos como forma de manter seus títulos atrativos.

A variável VAL apresentou relação estatisticamente significante e negativa com o retorno das ações, indicando assim, uma relação diferente daquela esperada e divergente com estudos anteriores, no entanto, de acordo com Lucena e Pinto (2008), Diniz (2011) e Bortolluzo et al. (2016). Talvez esta relação possa ser explicada ao considerar que as empresas com alto valor de mercado em relação ao patrimonial geralmente são empresas inovadoras, que atuam na área de tecnologia e apresentam alto valor de capital intelectual, o qual não é representado contabilmente, por este motivo, há valorização e seus títulos possibilitam retornos anormais que não podem ser explicados simplesmente pela análise das informações contábeis. Para Bortoluzzo et al. (2016) este fenômeno pode ter se dado pelo fato de não existir empresas que caracterizam-se perfeitamente como de crescimento no mercado de capitais brasileiro, não confirmando a anomalia de valor.

O fator rentabilidade indica que empresas com alta capacidade de transformar sua receita em lucros se beneficiam deste fator para se valorizar no mercado de capitais, uma vez que a distribuição de dividendos por parte destas empresas possibilita uma rápida elevação do preço dos títulos, conforme Fama e French (2015). Indica também a preferência dos investidores por empresas consolidadas no mercado as quais propiciam menor risco, corroborando assim com a hipótese de estudo $\mathrm{H}_{1}$.

Adicionalmente, Novy-Marx (2013) sugere que empresas com maiores lucros conseguem formar reservas, as quais podem ser utilizadas em momentos de maior necessidade, reduzindo o endividamento ou eliminando a necessidade de se financiar por capitais de terceiros, desta maneira, reduzindo a volatilidade dos seus títulos, que se tornam mais previsíveis, seguros e consequentemente rentáveis ao longo do tempo.

Em análise do fator relacionado ao nível de investimento das empresas (INV) evidencia-se que uma estratégia mais agressiva beneficia o retorno das ações apresentando significância estatística ao nível de $5 \%$. Vieira et al. (2017) relata que esta relação faz sentido ao se considerar empresas do setor industrial, as quais necessitam de grande quantidade de investimentos em ativos e tem atividade atrelada à circulação de bens de capital, desta maneira, tornando-se sensível à variação do seu patrimônio imobilizado.

Ainda sobre os investimentos, segundo Machado, Faff e Silva (2017), os diferentes níveis de investimento não são considerados relevantes para a explicação de retornos futuros. 
Crises e precificação de ativos no mercado de capitais brasileiro:

Os Cinco Fatores de Fama \& French

Esta relação talvez seja explicada devido a uma escolha de indicador não ajustado ao objetivo da análise ou pelo fato de os investidores não consideraram a variação do ativo total de uma companhia ao fazer sua decisão de investimento, principalmente pelo motivo das empresas brasileiras terem seus ativos de tamanhos similares. Desta maneira, este resultado indica a rejeição da hipótese de estudo $\mathrm{H}_{2}$.

Portanto, mediante a análise das variáveis presentes no modelo de cinco fatores, constata-se que todas são estatisticamente significantes, inclusive os dois fatores acrescidos recentemente. Em relação à variável rentabilidade, foi verificada a relação esperada, com sinal positivo confirmando a premissa da hipótese $\mathrm{H}_{1}$. Contudo, o fator nível de investimento não permitiu corroborar a hipótese $\mathrm{H}_{2}$.

Analisando o recorte temporal definido como crise internacional, verificou-se que algumas das variáveis modificaram sua relação com o retorno das ações, em comparação à amostra completa e ao período pré-crise, no qual havia estabilidade econômico-financeira.

Durante a crise internacional, o fator risco perde sua significância, indicando assim, que pode haver melhores indicadores de risco, conforme já evidenciado nos estudos de Fama e French (1992), Serra e Martelanc (2014) e Noda, Martelanc e Kayo (2016). Segundo Santos e Montezano (2011), uma análise de risco que considera os diferentes estados da economia se constitui em uma abordagem mais adequada para mensuração do risco do que pela utilização do beta de mercado.

Ainda sobre o período de crise, observa-se as inversões de sinais para o fator tamanho passando para uma relação positiva, corroborando assim com a hipótese de estudo $\mathrm{H}_{3}$. Esta relação também foi constatada no estudo de Mussa, Famá e dos Santos (2012) e pode encontrar justificava ao se considerar que em momentos de instabilidade, os investidores preferem realizar investimentos mais seguros, em empresas já consolidadas no mercado, visando reduzir os riscos, mesmo que isso represente menor rentabilidade em curto prazo. Oliveira, Silva e Martins (2016) complementam argumentando que empresas menores apresentam maior risco por impossibilitar ao investidor de se proteger mediante a aplicação de uma estratégia de diversificação.

Vale ressaltar ainda que, apesar de mais flexíveis, empresas menores apresentam estrutura de capital mais frágeis, ficando expostas ao risco macroeconômico, no qual havendo qualquer mudança na forma de identificação do mercado pelos produtos e serviços oferecidos por esta organização ou mesmo na escassez dos insumos necessários à manutenção de suas atividades pode levar á necessidade de endividamentos desproporcionais ao seu tamanho ou mesmo à falência. Soma-se a isso o fato de que em períodos de crise, devido à baixa liquidez, empresas de menor porte podem ter seus valores de mercado drasticamente alterados mediante pequena quantidade de ordens de venda, principalmente se houver fundos de investimentos tentado liquidar suas posições para recompor eventuais perdas ou para viabilizar a formação de caixa nos seus países de origem.

Ao analisar o período subsequente à crise internacional, observa-se claramente o retorno dos fatores de risco às suas condições gerais, apresentando resultados idênticos aos do período geral, sendo que o único destaque é a perda de significância estatística do fator risco, apenas corroborando mais uma vez Santos e Montezano (2011) que o beta de mercado não se constitui em uma medida adequada de risco.

Por fim, em uma análise do período de recessão nacional, verifica-se que os fatores se comportaram de maneira idêntica ao período geral, sem os recortes temporais. Contudo, ressalta-se que a passagem por períodos conturbados foi importante para moldar a maneira pelo qual os acionistas passaram a analisar suas opções de investimento através dos fatores 
Kleverson Dáliton Silva Moreira, Antonio Sergio Torres Penedo, Vinicius Silva Pereira e Marcelo Augusto Ambrozini

de risco aqui estudados. Esta construção parte de um momento de estabilidade econômica, na qual não havia preocupação em analisar os fatores relevantes, passa por um período de crise, no qual se deu atenção especial aos fatores tamanho e nível de investimentos como forma de tornar as aplicações menos arriscadas, seguido por um novo momento de estabilidade, que permitiu a inclusão de novos conhecimentos nas análises, os quais contribuíram para que os investidores vivenciassem um momento de recessão nacional com menos impactos do que aqueles observados na Crise Internacional, nos anos de 2008 e 2009.

Portanto, devido à busca por investimentos menos arriscados, os resultados corroboram com a hipótese $\mathrm{H}_{3}$ para o período de crise internacional e com a $\mathrm{H}_{4}$ para o período de recessão nacional.

Os resultados observados no período de recessão nacional para a variável nível de investimento corroboram a hipótese $\mathrm{H}_{4}$, mediante a existência de uma relação positiva entre a quantidade de investimentos, calculado pela variação do ativo total, com o retorno proporcionado pelas ações negociadas no ambiente da B3. A comprovação desta hipótese implica na compreensão por parte dos investidores de que, em conformidade com Lin (2017) e Vieira et al. (2017), em cenários macroeconômicos desfavoráveis, seja mais vantajoso o reinvestimento dos lucros auferidos por parte da empresa em projetos potencialmente rentáveis, em detrimento à distribuição de dividendos, o que pode levar a um crescimento dos resultados operacionais e consequentemente à geração de valor ao acionista no futuro.

Apesar da necessidade de proteção ao acionista em países emergentes, como o Brasil, a possibilidade de participação nos lucros obtidos a curto prazo e à imprevisibilidade do retorno dos projetos de investimento apresentados pelas organizações, os investidores que operam no âmbito da B3 passaram a compreender que os programas de pesquisa e desenvolvimento, alinhados a processos de inovação e aumento de eficiência podem permitir a obtenção de retornos anormais, às vezes até exponenciais, apenas na valorização dos títulos negociados, tornando positiva a relação entre investimentos mais agressivos e retorno das ações.

Desta maneira, pode-se entender que de acordo com os resultados apresentados e corroborando os estudos de Oliveira, Silva e Martins (2016) e Bortoluzzo et al. (2016), os fatores de risco componentes do Modelo de Cinco Fatores de Fama e French, apresentam comportamento condicional à situação econômica do país e que esta adaptação do comportamento se faz necessária para o desenvolvimento do mercado de capitais como um todo.

\section{CONSIDERAÇÕES FINAIS}

Este estudo teve como objetivo principal aplicar o modelo de cinco fatores e analisar o comportamento destes em relação ao retorno das ações das empresas listadas na B3, diferenciando o período de análise em pré-crise internacional, crise internacional, pós-crise internacional, recessão nacional e geral, com o intuito de esclarecer esta relação e compreender como instabilidades econômicas afetam a mesma.

Os resultados obtidos evidenciam que o modelo de cinco fatores ajusta-se bem ao mercado de capitais brasileiros uma vez que todos os fatores, em algum momento tiveram sua relação comprovada. Focando nas variáveis acrescidas ao modelo na pesquisa de Fama e French (2015), quais sejam a rentabilidade e o nível de investimentos, observou-se que a primeira se apresentou estatisticamente significante e com sinal positivo em quatro períodos, dos cinco analisados, estando de acordo com o sugerido pelos autores e corroborando a hipótese $\mathrm{H}_{1}$ do presente estudo. 
Crises e precificação de ativos no mercado de capitais brasileiro:

Os Cinco Fatores de Fama \& French

Com a aceitação da hipótese $\mathrm{H}_{1}$, entende-se que empresas com rentabilidade robusta geram valor aos seus acionistas a curto prazo, pela distribuição de dividendos e tornam-se investimentos mais seguros e previsíveis, de acordo com Fama e French (2015) e Novy-Marx (2013), através da elevação do seu fluxo de caixa, redução de endividamento, formação de reservas, redução de custos pelo ganho de escala e processos mais eficientes. Assim, a rentabilidade pode ser um fator determinante para a consideração de um acionista investir ou não em determinada empresa.

A segunda variável incluída ao modelo por Fama e French (2015), nível de investimento, apresentou relação positiva com o retorno das ações, contrariando o proposto pelo autor, explicitando a preferência dos acionistas em ter seu rendimento através da valorização dos títulos negociados em detrimento do recebimento de dividendos, rejeitando a hipótese $\mathrm{H}_{2}$. Para Vieira et al. (2017), esta relação faz sentido principalmente ao compreender que grande parte das empresas negociadas na B3 são industriais e dependem da realização de investimentos possibilitando a movimentação dos bens de capital necessários à manutenção de suas atividades.

Considerando os períodos de crise incluídos ao modelo por esta pesquisa, corroborando os estudos de Oliveira, Silva e Martins (2016) e Bortoluzzo et al. (2016), observou-se que a situação macroeconômica do país influencia a relação das variáveis de estudo, principalmente o fator tamanho e nível de investimento.

Diante do exposto, notou-se a existência de uma relação positiva entre o tamanho das empresas e o retorno das ações no período de crise internacional, de acordo com o esperado ao se sugerir a hipótese $\mathrm{H}_{3}$. De acordo com Mussa, Famá e dos Santos (2012) e Oliveira, Silva e Martins (2016) esta relação tem a ver com o menor risco ao seu investir em empresas de grande porte, com comprovada resiliência no mercado e capacidade de se manter viável ao atravessar por períodos de instabilidade econômica.

Por fim, houve a confirmação da hipótese $\mathrm{H}_{4}$, segunda a qual, o nível de investimento apresenta uma relação positiva com o retorno das ações em períodos de crise. A relação indicada foi verificada no período de recessão nacional e significa, segundo Lin (2017) e Vieira et al. (2017), que dada a imprevisibilidade e escassez de investimentos atrativos, os acionistas optam por investir em empresas que tenham projetos de investimentos agressivos, buscando alcançar retornos anormais pela valorização dos seus títulos, em detrimento de recebimento de dividendos.

Portanto, esta pesquisa atingiu o seu objetivo ao constatar que o modelo de Cinco Fatores desenvolvido por Fama e French (2015) é aplicável no mercado de capitais brasileiro mediante a verificação de existência de relação estatisticamente significante para todos eles, mesmo que em diferentes estados da economia.

Também constatou-se que em períodos de crises, independente da origem, existe distinção das relações encontradas e que nestes momentos os investidores optam por aplicar seu capital em empresas que propiciam menor risco, visando à manutenção do seu capital em detrimento da possibilidade de maiores rendimentos ou também grandes prejuízos.

Contudo, este estudo apresentou limitações por não haver a possibilidade de analisar um período maior como utilizado por Fama e French (2015c) e Kubota e Takehara (2018) o que poderia conferir maior confiabilidade estatística aos dados, bem como a análise de outros períodos de crise. Além disto, existiria ainda a possibilidade de fazer a análise por setores da economia da mesma maneira que Oliveira, Silva e Martins (2016) fizeram para a Europa, tendo em vista que cada um apresenta especificidades e que dentro destes, pode haver relações distintas daquelas encontradas, sobretudo em momentos de crise, no qual um setor pode 
Kleverson Dáliton Silva Moreira, Antonio Sergio Torres Penedo, Vinicius Silva Pereira e Marcelo Augusto Ambrozini

sentir os efeitos de maneira mais vigorosa do que nos demais, efeitos estes não capturados ao se analisar todos os portfólios de maneira geral. Por fim, pode-se sugerir que para estudos futuros existe ainda a possibilidade de adicionar dados referentes a outros fatores de risco ou mesmo de indicadores macroeconômicos específicos ao modelo visando confirmar as evidências aqui encontradas.

\section{REFERÊNCIAS}

ALDRIGHI, D. M.; CARDOSO, A. D. Crises cambiais e financeiras: uma comparação entre América Latina e Leste Asiático. Economia e Sociedade, Campinas, v. 18, n. 1, p. 61-117, 2009. DOI: 10.1590/S0104-06182009000100003.

BANZ, R. The relationship between return and market value of common stocks. Journal of Financial Economics, Rochester, v. 9, n. 1, p. 3-18, 1981. DOI: 10.1016/0304-405X(81)900180 .

BERGMANN, D. R.; GALENO, M. M.; SECURATO, J. R.; SAVOIA, J. R. F. Avaliação do CAPM condicional não paramétrico no mercado de ações do Brasil. Ciências da Administração, Florianópolis, v. 16, n. 38, p. 213-227, 2014. DOI: 10.5007/2175-8077.2014v16n38p213.

BORTOLUZZO, A.B.; VENEZUELA, M.K.; BORTOLUZZO, M.M.; NAKAMURA, W.T. Influência da crise financeira de 2008 na previsibilidade dos modelos de apreçamento de ativos de risco no Brasil. Revista Contabilidade \& Finanças, São Paulo, v. 27, n. 72, p. 408-420, 2016. DOI: 10.1590/1808-057X201603220.

BREALEY, R. A., MYERS, S. C., ALLEN, F. Principles of corporate finance. The McGrawHill/Irwin, 10. ed. 2011.

CAGNIN, R. F.; PRATES, D. M., FREITAS, M. C.; NOVAIS, L. F. A gestão macroeconômica do governo Dilma (2011 e 2012). Novos estudos - CEBRAP, São Paulo, n. 97, p. 169-185, 2013. DOI: 10.1590/S0101-33002013000300011.

CASTRO, B. R.; MINARDI, A. M. A. F. Comparação do desempenho dos fundos de ações ativos e passivos. Revista Brasileira de Finanças, Rio de Janeiro, v. 7, n. 2, p. 143-161, 2009.

CHIAH, M.; CHAI, D.; ZHONG, A.; LI, S. A better model? An empirical investigation of the Fama-French Five-factor Model in Australia. International Review of Finance, v. 16, p. 595638, 2016. DOI: 10.1111/irfi.12099.

COHEN, R. B.; GOMPERS, P. A.; VUOLTEENAHO. Who underreacts to cash-flow news? Evidence from trading between Individuals and institutions. Journal of Financial Economics, Rochester, v. 66, p. 409-462, 2002. DOI: 10.1016/S0304-405X(02)00229-5.

DINIZ, R. R. Análise dos Modelos de Fama e French (1992) e Carhart (1997). Utilizando as ações do setor da Construção e Transportes da Bovespa. 2011. 104 f. Dissertação (Mestrado em Administração) - Universidade Federal de Pernambuco, Recife, 2011. 
Crises e precificação de ativos no mercado de capitais brasileiro:

Os Cinco Fatores de Fama \& French

FAIRFIELD, P. M.; WHISENANT, J. S.; YOH, T. L. Accrued earnings and growth: Implications for future profitability and market mispricing. The Accounting Review, Stanford, v. 78, n. 1, p. 353-371, 2003. DOI: 10.2308/accr.2003.78.1.353.

FAMA E., FRENCH, K. A five-factor asset pricing model. Journal of Financial Economics, Rochester, v. 116, p. 1-22, 2015. DOI: 10.1016/j.jfineco.2014.10.010.

FAMA E., FRENCH, K. Dissecting anomalies with a Five-Factor Model. The Review of Financial Studies, v. 29, n. 1, 2016. DOI: 10.1093/rfs/hhv043.

FAMA E., FRENCH, K. International tests of a five-factor asset pricing model. Journal of Financial Economics, Rochester, v. 123, p. 441-463, 2017. DOI:

10.1016/j.jfineco.2016.11.004.

FAMA, E, FRENCH, K. Common risk factors in the returns on stocks and bonds. Journal of Financial Economics, Rochester, v. 33, n. 1, 1993. DOI: 10.1016/0304-405X(93)90023-5.

FAMA, E, FRENCH, K. Dissecting Anomalies. The Journal of Finance, v. 63, n. 4, 2008. DOI: 10.1111/j.1540-6261.2008.01371.x.

FAMA, E, FRENCH, K. The cross-section of expected stock returns. Journal of Finance, v. 47, n. 2, 1992. DOI: 10.1111/j.1540-6261.1992.tb04398.x.

FAMA, E, FRENCH, K. The value premium and the CAPM. The Journal of Finance, v. 61, n. 5, 2006. DOI: 10.1111/j.1540-6261.2006.01054.x.

FAMA, E. Efficient Capital Markets: A review of theory and empirical work. Journal of Finance, v. 25, n. 2, 1970. DOI: 10.2307/2325486.

FARIA, L. E. C.T.; NESS JR, W. L.; KLOTZLE, M. C.; PINTO, A. C. F. Análise da utilização de um modelo de quatro fatores como ferramenta auxiliar para gestão de carteiras baseadas no IBrX. Brazilian Business Review, Vitória, v. 8, n. 4, p. 70-93, 2011. DOI:

10.15728/bbr.2011.8.4.4.

GARCIA, R.; GHYSELS, E. Structural change and asset pricing in emerging markets. Journal of International Money and Finance, v. 17, p. 455-473, 1998. DOI: 10.1016/S02615606(98)00010-2.

GONÇALVES JUNIOR, W.; EID JUNIOR, W. Determinantes do investimento estrangeiro no mercado de capitais brasileiro. Revista Brasileira de Finanças (online), Rio de Janeiro, v. 14, n. 2, p. 189-224, 2016. DOI: 10.12660/rbfin.v14n2.2016.56461.

GUO, B., ZHANG, W., ZHANG, Y., ZHANG, H. The five-factor asset pricing model tests for the Chinese stock market. Pacific-Basin Finance Journal, Elsevier, v. 43(C), p. 84-106, 2017. DOI: 10.1016/j.pacfin.2017.02.001. 
Kleverson Dáliton Silva Moreira, Antonio Sergio Torres Penedo, Vinicius Silva Pereira e Marcelo Augusto Ambrozini

HAUGEN, R. A.; BAKER, N. L. Commonality in the determinants of expected stock returns. Journal of Financial Economics, v. 41, p. 401-439, 1996. DOI: 10.1016/0304-405X(95)00868$\mathrm{F}$.

JENSEN, G.; JOHNSON, R.; MERCER, J. Business conditions, monetary policy, and expected security returns. Journal of Financial Economics, v. 40, n. 2, p. 213-237, 1996. DOI: 10.1016/0304-405X(96)89537-7.

JENSEN, G.; JOHNSON, R.; MERCER, J. New evidence on size and price-to-book effects in stock returns. Financial Analysts Journal, v. 53, n. 6, p. 34-42, 1997.

KUBOTA, K., TAKEHARA, H. Does the Fama and French five-factor model work well in Japan? International Review of Finance, v. 18, p. 137-146, 2018. DOI: 10.1111/irfi.12126.

L'HER, J.; MASMOUD, T.; SURE, J. Evidence to support the four-factor pricing model from the Canadian stock market. Journal of International Financial Markets, Institutions and Money, v. 14, n. 4, p. 313-328, 2004. DOI: 10.1016/j.intfin.2003.09.001.

LA PORTA, R.; DE SILANES, F. L.; SHLEIFER, A.; VISHNY, R. Agency problems and dividend policy around the world. Journal of Finance, v. 55, p. 1-33, 2000. DOI: 10.1111/00221082.00199.

LEE, E.; STRONG, N.; ZHU, Z. Did the value premium survive the subprime credit crisis? The British Accounting Review, v. 46, p. 166-178, 2014. DOI: 10.1016/j.bar.2014.02.005.

LIN, Q. Noisy prices and the Fama-French five-factor asset pricing model in China. Emerging Markets Review, Elsevier, v. 31(C), p. 141-163, 2017. DOI: 10.1016/j.ememar.2017.04.002.

LUCENA, P.; PINTO, A. C. F. Anomalias no mercado de ações brasileiro: uma modificação no modelo de Fama e French. RAC-Eletrônica, Curitiba, v. 2, n. 3, p. 509-530, 2008.

MACHADO, M. A. V.; FAFF, R.; SILVA, S. C. S. Applicability of investment and profitability effects in asset pricing models. RAC - Revista de Administração Contemporânea, v. 21, n. 6, p. 851-874, 2017. DOI: 10.1590/1982-7849rac2017170027.

MÁLAGA, F.K. Retorno de ações: Modelo de Fama e French aplicado ao mercado acionário brasileiro. 1. ed. São Paulo: Saint Paul, 2005.

MARKOWITZ, H. Portfolio selection. The journal of finance, v. 7, n. 1, p. 77-91, 1952.

MATOS, P. R. F.; ROCHA, J. A. T. Ações e fundos de investimento em ações: fatores de risco comuns? Brazilian Business Review, Vitória, ES, v. 6, n. 1, p. 22-43, 2009.

MILLER, M.; MODIGLIANI, F. Dividend policy, growth, and the valuation of shares. Journal of Business, v. 34, p. 411-433, 1961. DOI: 10.1086/294442. 
Crises e precificação de ativos no mercado de capitais brasileiro:

Os Cinco Fatores de Fama \& French

MUSSA, A.; FAMÁ, R.; SANTOS, J. A. A adição do fator de risco momento ao modelo de precificação de ativos dos três fatores de Fama \& French aplicado ao mercado acionário brasileiro. REGE - Revista de Gestão, São Paulo, v. 19, n. 3, p. 453-471, 2012. DOI: 10.5700/rege473.

NODA, R. F.; MARTELANC, R.; KAYO, K. O fator de risco lucro/preço em modelos de precificação de ativos financeiros. Revista Contabilidade \& Finanças, São Paulo, v. 27, n. 70, 2016. DOI: 10.1590/1808-057x201412060.

NOVY-MARX, R. The other side of value: The gross profitability premium. Journal of Financial Economics, v. 108, p. 1-28, 2013. DOI: 10.1016/j.jfineco.2013.01.003.

OLIVEIRA, I. M. M.; SILVA, F. C. C. C. S.; MARTINS, F. V. S. A relação (não) condicional dos fatores de risco mercado, dimensão e valor: Evidência em cinco países da Europa. Revista de Gestão, Finanças e Contabilidade, Salvador, v. 6, n. 3, p. 177-195, 2016. DOI: 10.18028/2238-5320/rgfc.v6n3p177-195.

PEIXOTO, F. M. Governança corporativa, desempenho, valor e risco: estudo das mudanças em momentos de crise. 2012. 216 f. Tese (Doutorado em Administração) - Universidade Federal de Minas Gerais, Belo Horizonte, 2012.

ROGERS, P.; SECURATO, J. R. Comparative study of CAPM, Fama and French model and reward beta approach in the Brazilian market. SSRN Electronic Journal, 2007. DOI: 10.2139/ssrn.1027134.

SALLABERRY, J. D.; MEDEIROS, O. R. Os efeitos da crise financeira de 2008 no valor das empresas e nos ativos intangíveis. Revista Contemporânea de Contabilidade, Florianópolis, v. 12 , n. 27 , p. 187-205, 2015. DOI: 10.5007/2175-8069.2015v12n27p187.

SERRA, R. G, MARTELANC, R. Hierarchical determinants of Brazilian stock returns during the 2008 financial crisis. Emerging Markets Finance \& Trade, v. 50, p. 51-67, 2014. DOI: 10.2753/REE1540-496X5005S404.

SHILLER, R. J. From Efficient Markets Theory to Behavioral Finance. Journal of Economic Perspectives, v. 17, n. 1, p. 83-104, 2003. DOI: 10.1257/089533003321164967.

STULZ, R. M. Globalization, corporate finance, and the cost of capital. Journal of Applied Corporate Finance, v. 12, p. 8-25, 1999. DOI: 10.1111/j.1745-6622.1999.tb00027.x.

TITMAN, K. C. S.; WEI, J.; XIE, F. Capital investments and stock returns. The Journal of Financial and Quantitative Analysis, v. 39, n. 4, p. 677-700, 2004. DOI: 10.1017/S0022109000003173.

VIEIRA, D. V. V.; MAIA, V. M.; KLOTZLE, M. C.; FIGUEIREDO, A. C. Modelo de cinco fatores de risco: Precificando carteiras setoriais no mercado acionário brasileiro. Revista Catarinense de Ciência Contábil, v. 16, n. 48, p. 86-104, 2017. DOI: 10.16930/2237-7662/rccc.v16n48.2376. 